\title{
Current developments in international trade - an opportunity for a new progressive approach in economic policies
}

\author{
Volker Heinemann \\ Green Economics Institute \\ 166 Divinity Road \\ Oxford, OX4 1LR, UK \\ E-mail: volkerheineman@yahoo.de
}

\begin{abstract}
This paper explains the main current developments effecting the structures and characteristics of international trade. These recent developments and changes in the way how trade occurs and what is traded cannot be explained with traditional trade theories. Despite a fundamental change in the global economic environment the suggestions for optimal economic policies based on the conventional theories are still forming the framework to discuss international trade policies or make recommendations for the appropriate trade regime or related international agreements. Based on a realistic empirically founded view new theoretical concepts and arguments need to be developed that lead to a different optimal trade regime than what is conventionally preferred. The paper summarises the arguments for such a change to occur and initiates the overdue and practically relevant debate to develop such a trade regime.
\end{abstract}

Keywords: international trade; globalisation; managed trade; intra-industry trade; Trans-National Corporations; TNCs; structuralism; developing economics.

Reference to this paper should be made as follows: Heinemann, V. (2007) 'Current developments in international trade - an opportunity for a new progressive approach in economic policies', Int. J. Green Economics, Vol. 1, Nos. 3/4, pp.351-373.

Biographical notes: Volker Heinemann is an Economist who studied at the Universities of Goettingen, Kiel and Nottingham. He is a specialist in international and developing economics, monetary economics and macroeconomic theory and policy. He is the author of the book Die Oekonomie der Zukunft (The Economy of the Future), a book outlining the principal structure for a modern economy that accepts the pressing changes required to the outdated current economic thinking. He is co-founder and Director of the Green Economics Institute, a member of the Institute of Chartered Accountants in England and Wales and Associate Editor of the International Journal of Green Economics. 


\section{Introduction}

Issues surrounding international trade are of exceptional importance not only for the scientific discipline of economics as such but also for political decision-making as a whole. A wide range of detailed economic decisions are determined or at least influenced by the international competitive environment. International competition is more frequently than ever before used to sway a political argument in favour of a preferred political outcome. We are furthermore told that this increasingly international economic environment is a given fact and inevitable due to its foundations in currently established market forces. International competition decides what we can or cannot do in a wide range of political areas. It appears to be that the restrictive elements imposed by this allegedly 'given' framework, despite being very restrictive for the individual, are accepted as unavoidable facts and therefore not contested by the wider general public.

Investments in environmental protection, increases in social standards, reducing working hours to enhance the work life balance and help to improve human happiness, or just generally allowing people to make decisions about their life independent from unadjusted market mechanisms, appear to be in contradiction to the logic of the natural laws of the international economy. Prevalent economic logic finds that as a consequence such investments should not be pursued. In short the mechanisms of the world economy force national economies back to a situation that many modern societies have left behind decades ago. Political achievements, in contrast to the apparent automatic results of free-market principles, were established nationally after decades of debate and democratic decision-making. The increasing dominance of the economic agenda by this particular interpretation of the merits of international trade, has even thrown into question the value and relevance of trade-regulation achieved at a national level.

By just moving the very same principal economic questions, questions about the right economic policies and how to implement them, one level higher, from the national to the international level, economic history repeats itself. As before, we are told that it is neither necessary nor possible to establish an organisational framework within which people can shape the system, rather than being shaped by it. Many political groups actively support such a repetition of history to prolong the life of their ideological basis and allegedly scientific arguments are put forward to support such claims. The current global neo-liberal mainstream economic trend, usually given the name 'globalisation' as far as international developments are concerned, is based on a concept that is frequently referred to as 'free' trade. As is increasingly clear, so called 'free-trade' does not maximise the freedom of the human beings involved in it, but rather subordinates people to the economic system. Such definitions are supported by political groups who cannot maintain their ideological basis without competitive pressures being maintained and enforced upon people and the derived political proposals are not criticised by the wider public due to a lack of understanding about the facts and about what degree of freedom of choice of economic policies really exists.

This criticism is not new. Many people share the critique of the current economic policies that contribute to the era of globalisation. There is in addition an increased recognition of the need for alternative explanations of the international economy with the suggestion that more sophisticated economic policies are required. Economists like Chang (2004), Grimwade (2000) and particularly on the role of trans-national corporations Ietto-Gilles (2005) have made substantial contributions to correct the 
established view of the international economy. Economic policies have become uninspiring, un-ambitious, reactionary, intellectually protective and there is a general tendency not to shape or design anything in society or the wider political framework. Rather, we just try to be quicker in following the trends the market forces dictate, regardless of whether this means that the standards desired by society are respected or a downward spiral of marginal and reactive decisions is initiated. Primitive shortsighted competition has replaced a more holistic long-term development of economic policies on the international level. This appears to be one of the main reasons why the age of globalisation has triggered such a strong and negative public reaction in the first place, a reaction that is surprisingly strongest outside the inner circles of economists which is a further indication that a true assessment of economic reality appears to be more easily possible if a less 'economic' but wider multidisciplinary perspective is taken. The intention of this article is to explain current structures of international trade in order to provide a sound foundation for arguments against the simple logic that mainstream economics still supports as far as international trade is concerned. On that basis, it will be possible to assess what degrees of freedom to shape the international economy are available and what intelligent economic policies for the globalised world are required to maximise the benefits of the people involved in the processes and to respect relevant wider social and environmental considerations. The article follows a previously well-established tradition of differentiated and realistic argumentation about what the economic system can achieve and to what extent economic policies and changes to human behaviour can effect economic development positively from that basis. Main economic thinkers with a wide range of different beliefs have contributed to the differentiated debate in the past like Keynes (1936), Schumpeter (1997) and Eucken (1990) with their original works in previous decades and more recently Greenaway and Shaw (1988), Olson (1991) and Paetzold (1998) with an excellent summary of stabilisation policies. All of these works provide a great depth of practical and relevant understanding that appears to have been lost from the ideological debate about economic issues in recent times.

\subsection{There is nothing neo or liberal in neo-liberal economics}

The most surprising thing in this context is that this neo-liberal revolution, that is particularly prominent in international economic debates, is based on a theoretical framework that in its core concepts dates back to the 19th century, but is portrayed as a new way of economic thinking. All more recent developments in this mainstream theory only reiterate the same fundamental logic, a strong belief in unadjusted market forces even for wider issues effecting society as a whole and the development of the world in general - there is nothing neo in the neo-liberal proposals. This will become clearer as the arguments progress in this article and more examples are given. Furthermore, the arguments used against more sophisticated economic policies proposed at the international level are identical to the arguments employed decades ago when on the national level political movements started to create modern, organised societies. In the past, political groups representing the interests of influential entrepreneurs argued against regulation at the national level - basing their arguments on the need to compete with foreign businesses unburdened by such regulation. The same argument and strategy is now repeated on the international level. Geography however does not change the basic principles of economics and does not make the old arguments more relevant. They have 
long been contradicted on the national level by appropriate legislation anyway. Trade is nowadays more international and therefore geographically different to the situation in the past, but the arguments put forward by either side are essentially unchanged and the consequences and objective solutions reached will eventually be the same. The question is only how much time is wasted until the truth is established now on the more abstract international level.

Over time, regulations and intelligent political frameworks were successfully implemented across wider and wider areas. This led to the collapse of the fundamental argument against regulation, which was seen to be shortsighted and irrelevant as soon as the appropriate level was chosen to address the subject. With this historical knowledge in mind it becomes unreasonable to follow undisputed mainstream arguments against the creation of economic frameworks to achieve desired results. We are told that regulation or design of market results is impossible due to the power of the market forces. However, we know that it can be done as it is already in place on a national level. What is required is to implement appropriate methods and policies in the different and much more complicated international framework, but it is by no means a fundamentally new request for political action.

It is, nevertheless, disappointing that theoretically weak and historically already contradicted arguments manage to influence even very progressive political groups in the belief that neo-liberal logic is inevitable in our current times. Since the decline of Keynesian economics at the end of the 1970s, the progressive political spectrum seems to have lost any long run economic direction and ambition. It lacks a comprehensive alternative concept for the future development of society and as a consequence exceptionally weak arguments continue to be recycled from that perspective that fail to have the potential to develop a true alternative to the current mainstream.

A lack of theoretical knowledge is apparent on both sides of the globalisation debate. As a consequence, there is a split of the public debate into either a very radical and theoretically questionable criticism of what is actually going on in the national and international economy and on the other side a tendency to follow the mainstream trend in economic thinking and argumentation more or less blindly, despite obvious and serious theoretical and practical deficiencies. Only mild adjustments or repairs to the traditional concepts are attempted whereas in fact the entire approach is flawed and some of the most commonly believed theoretical foundations can no longer explain present reality. The confusion is complete and the long-running debate does not appear to reach any sensible conclusion. Nor is there even a consensus which might be capable of providing the basis of an objective global political strategy, regardless of any relevant or individually preferred normative considerations that are simultaneously widening the spectrum of potential beliefs anyway.

\section{What is wrong with mainstream concepts?}

The aim of this article is quite simply to explain the basic fundamental concepts of international trade to help to avoid quite common misunderstandings about globalisation, that result in incorrect, overly radical criticisms that only aid the mainstream in its dismissal of alternatives to the unregulated outcomes of international markets. There needs to be a precise understanding what is wrong with the mainstream economic concepts, where the reality of international economics is not following the assumptions 
that mainstream economic thinking assumes to be in place and where normative concepts are skilfully introduced into the scientific work. It is essential to identify where this 'scientific' approach pushes for the normative ideas of the advocates themselves and not for truly scientifically supported facts. If the debate remains vague and unfocused, there is no progress achieved. Critical people continue talking to the same supportive audiences but do not achieve any impact on the unsupportive mainstream. The truth about international economics remains within a minority circle but never changes economics as a whole.

The area of international trade is currently one of the most interesting areas of economics where this huge problem of normative influence on scientific research is most easily observable, discernible and influencing practice. Many other areas of mainstream economic thinking need equally comprehensive adjustments but this will be the subject of future articles and research. Heinemann (2001) provides a wider criticism of various economic problems including the teaching of the discipline and the most important areas of the future economy.

\section{Current developments in international trade theory change the traditional perspectives and political options available}

In addition and linked to the critique of the traditional theoretical concepts of international trade, a line of more practical considerations will be developed. This second main stream of argumentation in this article will be about current developments in international trade. These developments open a window of opportunity for modern economic policies just at a time where many people who are principally supportive towards implementing economic policies are unable to find a suitable approach. They are also striving to re-interpret past and future trends in economic activity or theoretical explanations.

Great opportunities for modern economic policies are missed. Right at a time where traditional theories are unable to explain the current developments in international trade, the belief in the very same theories is used to convince national governments to make their policies fall into line with allegedly unavoidable trends in international economics. This article argues that the theoretical basis of international economic 'non-policy' has eroded and that the actuality of the international economy supports the implementation of policies to tackle concerns for justice and of the wider public. The main foundation for a different approach to assess the phenomenon called international trade will be provided. On that basis many more detailed questions can be answered and concepts developed, now based on a more factually correct strategic direction and a long term and normatively unbiased view of reality.

\section{Basic principles of international economics}

\subsection{Old ideas remixed and presented as new}

As in all areas of science there are thousands of articles and books available that cover international trade. Regardless of the volume of publications in this subject the basic principles behind the arguments remain the same. There is a strong tendency to 
trick people into the belief that new findings are behind new articles whereas the argumentation is nothing but a repetition of the same basic ideas in ever increasing detail - sometimes regardless of developments in reality. Really new ideas are rare and the attempt to 'proof' theories against reality, the main step in scientific research, is not even attempted. When one idea has lost steam in the public debate another similar idea is proposed, and after a number of ideas have lost their public appeal, the process can start at the beginning as the subject is so complex and abstract that the general public does not remember the arguments previously launched in detail anyway. Old ideas are warmed up again and again and an uninterested or uninspirational general public remains convinced that there is no alternative, especially if the general tone of the proposals and concepts is kept in line with the average public beliefs. Neo-liberalism is not neo and in many areas not liberal at all, but still forms the currently dominating set of economic thought.

\begin{abstract}
"The term 'neoliberalism' is used by economists in an ironic, when not in a downright derogatory sense to denote a confused ideology that has taken hold of the minds of businessmen, bankers, journalists and bureaucrats down to a vast number of politicians including left-wingers. It is quite a simple ideology and is based on two axioms, the market is efficient regardless of its form, the State is inefficient regardless of its institutions - a theory that no serious classical or neoclassical liberal would have ever supported." (Screpanti and Zamagni, 2005, p.460)
\end{abstract}

It is effectively a watered down monetarism, that itself went out of fashion very quickly for its radical and unrealistic bias, mixed with some classic economic concepts from the 19th century. There are constant demands to deregulate the economy to help achieve more growth and employment by more competition and pressure from market forces even in cases where countries like Germany achieve record exports (Sachverstaendigenrat zur Begutachtung der Gesamtwirtschaftlichen Entwicklung, various years) - a clear indication of competitive strength. The real problem is obviously the weak domestic demand in such countries, as demand is possibly depressed already due to people being kept in constant job insecurity for the sake of preservation of the traditional value base based on a competitive environment for society. This is a key strategy for the preservation of traditional ways of how the society is maintained that will be explained in detail later but initially it is an example that the neo-liberal concepts do not avoid normative interference or lobbying if it suits their long-term objectives regardless of any allegedly pure scientific argumentation for unadjusted competition and 'free' markets.

To understand the fundamental bias related to the particular subject of international trade, the driving force behind the logic of globalisation, it is important to identify and understand clearly what the fundamental principle of comparative advantage as a basis for beneficial trade is capable of explaining and what it can and cannot support. We will take this as the starting point to develop the more complex arguments that help to understand the current situation in which international trade occurs. This will lead us to a comprehensive understanding of the facts and the degree of freedom in the creation of economic policies.

\title{
4.2 The principle of comparative advantage
}

The principle of comparative advantage developed by Ricardo (1821) explains that trade between countries is based on countries specialising in what they can relatively (not absolutely) produce best - which means in comparison to all products the country itself 
produces. The comparison is therefore between the own products (of a respective country) and it is enough to specialise in what is relatively produced best, even if this product or products are produced less favourably in direct, absolute comparison with a product of the competing country. The principle of absolute advantage, which can be indirectly derived from writings of Smith (1776), that an absolute advantage, a comparison between countries (not between the products of the same country), is necessary to trade is therefore seen to be irrelevant. All countries can trade with each other because there is logically always at least one product that can relatively be produced best in that country compared to all other products of that same country and this is sufficient for trade to occur.

This principle of 'comparative' rather than 'absolute advantage' appears to be difficult to understand for many people. As a consequence, there are constant attempts to prove this concept fundamentally wrong by people who are critical of foreign trade as it happens to be increasingly the case in the era of globalisation. This attempt to prove the concept logically wrong is a waste of time as the concept is in fact completely correct. Such unfounded criticism furthermore creates additional confusion and distracts from the real problems created by wrong interpretations and inappropriate application of this concept. People who accept this principle of comparative advantage passionately tend to exaggerate the power of the concept. Such exaggeration makes these people blind to any meaningful proposals for corrections to any undesirable results that occur in unadjusted trade regimes. These are based on the belief that everything develops to optimal solutions without the need for any policies based on conscious reflection of what is going on in reality. Such statements and beliefs are a worthwhile area for criticism, not the attempt to criticise the concept itself.

Arguments are frequently raised, for example, that try to undermine the principle by such questions as, "what happens if a country looses its comparative advantage?". This clearly indicates that the principle was not understood. A country can have different comparative advantages over time as the economy is a constantly changing evolutionary system, but there is always at least one product with a comparative advantage (relative to all other products of that country) even if there is no single absolute advantage (a direct comparison of products between countries and not within a country). It is therefore logically impossible to loose a comparative (relative) advantage, the loss of one advantage will only move this advantage to a different product, not eliminate it. Based on such misunderstandings between comparative (relative) and absolute advantage further observations are brought into the picture and it is proposed that there will be problems in international trade due to the fact that "China has not only a comparative advantage but also absolute advantages in almost everything" (Woodin and Lucas, 2004). Again such statements referring to absolute advantages are all irrelevant and do not contradict the principle of comparative advantage in any way. Neither is the invention of the term 'absolute profitability' in the same publication helpful as the delicate difference between absolute and relative (comparative) properties of a phenomenon is simply irrelevant as far as profits are concerned. Profits are not objects on which any decisions are taken, on whatever basis this is done, as is the case with traded goods. Profits are just the result of economic activity, a measure of success not an object, like goods that can be compared with each other to find which is most efficiently produced in different geographical locations. Profits are altogether a completely different thing (there is no such thing as a 
relative, comparative profit) which should not be confused with issues of what products are traded under what terms which form the basis of trade theory.

The principle of comparative advantage just says that there is the possibility that trade occurs even with absolute advantages being all accumulated by one country. The reason is that by specialising in relatively advantageous production a country can utilise its production factors better. If this is done in all participating countries the overall production potential is maximised. On that basis the countries trade in the specialist goods they produce. Even a country that has absolute advantages in all production processes can gain further by specialising in the best process of them all. This benefit will compensate for the disadvantage of having to import goods that are slightly less beneficially produced in another country (based on an absolute comparison between the products but are relatively best produced based on a relative comparison of all products of that country). It is in turn to the benefit of that country to specialise in what it can relatively do best.

All these decisions to specialise appropriately according to the theory depend at least on some pressure towards an equilibrium in the balance of trade between the participating countries. There is an ongoing debate about the underlying assumptions of the concept. If this debate is however not focused on what really matters, the discussion will only distract from the main issues that have to be understood and addressed for the sake of generating a meaningful public debate about the subject.

To move the critical argumentation about this fundamental and logically undeniable principle of international trade to a more meaningful level, we need to explore the limitations of it as there is a tendency to use this principle to declare all trade policies as irrelevant, unnecessary and damaging, as they spoil the already perfect situation that is derived automatically and allegedly based on this fundamental logic. This is the same simplification that occurs very frequently in other areas of economics where the complexity of reality is lost when models based on generalised assumptions are used unadjusted and without regard for the limitations of those underlying assumptions to make arguments about reality.

Comparative advantage is frequently used to justify the concept of free, actually better called 'unregulated' trade. The assumption is made that the pure logic of the concept ensures that there are no further considerations to be taken into account - considerations that may result in problems that require a higher level of decision making to correct the initial outcomes of the principle. The problem is that in fact the entirely theoretical idea is undeniably correct as such. The principle of comparative advantage itself, which represents only a description theory, a description of an idea that may have some merit in explaining what might work, is now mutated into an 'explanation theory', which tries to explain why the reality has to be as it is. In general, theoretical principles are only as good as the quality of the underlying assumptions. It is therefore not correct to argue that the principle of comparative advantage proves anything in reality, and certainly does not give a blank mandate to unregulated trade. This requires a completely different layer of reasoning where, without empirical evidence, no meaningful theories can be derived or supported. A simple, logically pure concept, however correct, is clearly insufficient to explain economic realities, and leads to confused and incorrect conclusions. 


\subsection{The complexity of the international economic reality}

The problem with criticising many mainstream economic concepts is precisely the situation described above. That they are constructed in such a way and with such assumptions that if stated correctly then, as such, the ideas are correct. Problems begin however with the deliberate development of a great number of concepts all suggesting an intentional and preferred characteristic as being a truth. Alternative ideas - and this is the crux - are not utilised in the same way for model building. Every journalist knows how perfectly one can lie by just telling only half of the truth.

Furthermore there is a general problem with reducing the complexity of reality, deriving arguments based on such reductions and then using the unadjusted conclusions to explain a complex reality. Criticism is usually brushed aside with comments to the effect that there is no alternative to the reduction of the complexity of information. This response misses the point as this defence is focused on the initial reduction stage not the stage where the derived concepts are referred back to reality where most of the problems occur. There are further practical problems and manipulations performed when basic findings are exaggerated in strength and presented as valid to explain reality at the stage when the results are transferred back into a complex situation. This is the step that really matters. It is the final part in the chain of information flow and argumentation where the practical problems occur, and not the initial information gathering and reduction for the purpose of model building. There is thus a fundamental confusion between the theoretical logic and the outcomes in practice. The logic does work but theory does not fit empirically verifiable reality.

It is time to have a specific look at what is actually occurring in international trade and what cannot be explained by the core principles of mainstream economics mentioned above. I first try to highlight the main limitations of the principle of comparative advantage that should make it clear that it cannot be the ultimate explanation of issues about globalisation and international trade in our present time and then will swiftly move on to more recent developments in international trade that crystallise the argument for a new assessment of the situation. This will then hopefully open a less ideological and biased debate concerning international economics in the future and it should make it apparent that realistic assessments of the subject must now derive a highly beneficial trade system for the future which will avoid any fall back into economic situations that deprive people of their freedom to determine their lives. Needless to say that this article emphasises the great potential this international arena has for progressive economic strategies, especially if the subject is addressed with the right theoretical foundation and based on facts alone. If used intelligently, international economic aspects can become the foundation for modern and progressive economic policies from which other serious deficiencies of conventional economic thinking can be identified and then reformed.

There are a number of already well-known arguments that have been developed over time which help to make the assessment of the principle of comparative advantage and its appropriate practical use more realistic and more relevant. These arguments are presented here again as they indicate and explain the general deficiencies of conventional economic thinking and will become important for the development of suitable foundations for alternatives later on. Generally speaking, trade theory struggles to explain the more recent development in economic reality. 
"There has been a growing sentiment, however, that comparative advantage based on factors of production is not sufficient to explain patterns of trade. More broadly, much of the world trade takes place between advanced industrial nations with similar factor endowment. At the same time, researchers have documented the large and growing volume of trade in products whose production involves similar factor proportions. Both types of trade are difficult to explain with the theory." (Porter, 1990, p.12).

We will in turn now look at some of the problems with this standard trade theory and where the traditional view needs to be corrected to be of any value for the explanation of current international trade realities.

\subsection{Comparative advantage is a static concept}

The principle of comparative advantage is an entirely static concept, the factor of 'time' does not play a role in it. This criticism is in line with the general observation in modern economics that the evolutionary factors appear to have been overlooked in this science. Much consideration is given to what situations exist, but no consideration is given to how these situations have been historically derived. This is in its own right a very important and interesting subject that can only partially be developed in this article. The comparative advantages are somehow a 'given' in conventional economic theory. The concept is not concerned with and does not explain their creation or development over time.

An advantage is presented as the unquestioned basis for trade even if such advantage is based on a history of undeniably unjust acts such as a the violent colonisation which helped the western world to lay the foundations of their industrialisation. Today, being already industrialised, the western world has the comparative advantage in the production of various industrial goods, while the developing world has consequently the comparative advantage in goods produced by cheap labour or certain products that grow in their climate. The developing world is forever trapped in the production of these items. As a logical result of these dynamic deficiencies the infant industry argument was developed at an early stage of international trade theory by the German economist Friedrich List (List, 1856), arguing for economic policies to allow infant industries to develop to a level so that they can help to reshuffle the distribution of comparative advantages.

The response from conventional economics to the infant industry argument only addresses detailed technical questions as to the efficiency of the policies suggested to tackle the problem, but not the initial criticism of the concept itself. Whether tariffs or subsidies might be more beneficial in the respective circumstances is the subject of the research, the original criticism of an unreasonable distribution of relative advantages can however not be fundamentally rejected with these detailed considerations. The debate is in turn significantly determined by the assumptions underlying the arguments and hence prone to the same problems with 'reductionist' approaches in general. The general concept of the infant industry argument has never really been challenged - the critical debate against the argument tends to be turning round in circles utilising ever increasing levels of intentional assumptions to maintain the original position taken, that the unadjusted market outcome takes care of everything relevant. This very simple infant industry argument however already forms a starting point for the development of appropriate corrective economic policies for international trade streams. These 'trade streams' take into account a more even distribution of advantages in order to overcome undesirable current situations and as such improve the international trade structure. They 
do not, therefore, damage the assumed perfect outcome from unregulated trade, as conventional economics claims.

Despite being incapable of overcoming the dynamic deficiencies of the basic principle on which conventional trade theory is founded, conventional economics pushes the case for an unregulated international trade regime. This case is made irrespective of any form of value judgement or concept of justice, despite the historical injustices that have lead to the current endowment and distribution of comparative advantages and disadvantages. Typical of the approach of the current mainstream economic thinking is this pattern of ignoring further details or consequences that lie outside very basic economic considerations. A further deficiency is that there is a reliance on developing simplistic methods linearly to the maximum, while not even questioning the starting point from which the typically marginal concepts of conventional economics are derived. Concepts like the 'Pareto efficiency' (Pareto, 1909) follow for example the same logic of dealing with marginal conditions of efficient market solutions without having anything to say about how the status quo they use as a starting point came into being.

\subsection{The terms of trade debate}

From a practical point of view the deficiencies of the belief that reality develops according to the pure principles of logic can be relatively easily criticised. Reality very soon delivers the opportunities to do so.

The 1970s saw an important debate about the development of the so-called terms of trade, a ratio that defines how much of one product needs to be produced to exchange a given quantity of another. This Prebisch/Singer hypothesis theoretically suggested much earlier (Prebisch, 1950; Singer, 1950) identified problems developing countries can face. It successfully predicted the actual development in international trade happening two decades later, where due to the overproduction of goods by to many countries supplying similar products, particularly in crops for the world market, the terms of trade for these countries declined. A comparative advantage always exists but developing countries faced a situation where they had to produce more and more to exchange for the same goods they required. As mentioned earlier, the basic principle of comparative advantage has not much to say about the equitability of an existing situation or the development over time of the distribution or structure of the relative advantages. In contrast, a green economics analysis is fundamentally concerned with such issues of social justice which appear to be missing in mainstream economics all too frequently.

\subsection{Balance of trade - deficit and surplus}

Further problems with the basic principle can be identified when the persistent trade deficit/trade surplus situations that many countries maintain are considered. From a strict interpretation of the benefits that can be derived from trade based on the principle of comparative advantage, it should be clear that the advantage lies in the gain from specialising in what can be best produced, and deducing that trading in these goods realises these benefits. To export more than is imported, is not supposed to be the intended strategy that the principal concepts suggest. However this is something many politicians appear to think of when they try to enhance the competitiveness of the domestic economy further although there are already balance of trade surpluses achieved by the country in question. 
If one country has a balance of trade surplus then at least one other country must have a balance of trade deficit which requires financing in the short term and a more fundamental solution to overcome the deficit situation based on changes to real economic activity in the long term. From a developing economics perspective it would even be beneficial if underdeveloped countries are allowed to run a positive balance of trade and if the developed world maintained reasonable deficits to help economic progress in the developing world by allowing countries to integrate themselves into the wider, global economy, ensuring they did not suffer serious financial difficulties based on deficits from the start.

The contrary is however more often than not the case. Conventional economics, despite highlighting the principle of comparative advantage in international trade debates, a concept that is based on the strict logic of gains from exchange not gains from surpluses, is surprisingly unwilling to criticise such practical deficiencies in international trade patterns despite their medium and long-term persistence. Regardless of any such considerations about what is beneficial for the integration of more countries into the world economy it is a matter of fact that the economic reality does not support the view that the balances of trade of different countries converge towards an equilibrium condition where exports and imports balance in value. The problem of a tendency or not towards a situation of a balance of trade equilibrium is dependent on other parameters or variables beyond the principle of comparative advantage. Some of the reasons for the persistence of surpluses or deficits can be found in the underlying assumptions of the principal, logic argumentation that may have been correct in the 19th century when the concept was developed but are now most certainly out of step with reality. The principle of comparative advantage is based on classic economic thinking, assuming for example an equilibrium situation in the labour market where the production factor labour is always fully employed. As we all know this is not the case in many countries today, developed countries and underdeveloped alike. In fact it is important to realise that if the assumption of full employment is relaxed and unemployment is assumed, the automatic tendency in the principle of comparative advantage towards specialisation in some goods and trading for the remaining goods is not that conclusive. Under full employment every specialisation in one process of production is only possible by taking production factors from other processes, this results in less production of those goods and automatically creates the trading opportunity for them from a different country. With plenty of production factors available, as it is the case in countries with unemployment, this situation alters. More goods than can currently be sold can be produced in such a country, further specialisation for export production is possible without having to purchase products from abroad to compensate for any losses in production potential. This is because there are no such losses as the production factor labour is still available from the pool of unemployed people. Arguments along these lines appear to illustrate that the basic concept about how trade is occurring are still valid. However they should not be used to explain the reality we live in or even try to tell us that the only sensible way to deal with international trade issues is by leaving the decision making to the market forces based on such simplistic concepts alone. This is however the foundation of the globalisation logic and the current trend in international economic thinking. This article will argue instead for an alternative, much more differentiated approach based on responsible decision making. 


\subsection{Principle approaches - unregulated trade, the structuralist approach and interdependence theories}

The fundamental problems with an entirely unregulated approach to international trade have already in the past led to splits in economic theory related to the subject. It is obvious from an empirical perspective that not every individual can be expected to follow the same inherent assumptions present in conventional economic thinking, especially if empirical research does not support the assumptions. Academic discourse itself is increasingly controversial. There are in addition numerous examples where international trade policies based on the standard stream of argumentation have failed to deliver the results that were promised. The empirical knowledge gained from decades of practical development economics policies indicates that the difficulty and complexity of the subject is far greater than the basic theory suggests, a repetition of the same principles now under the new name neo-liberal does not change this. A much greater degree of freedom for each individual country to design its own policies does not contradict the economic success of the economic policies applied. Quite the contrary, by not following the mainstream logic, an overall better path for development can be designed to the real benefit of the people involved.

The various streams of thought concerned with international trade theory can typically be grouped into three approaches to give the principal overview this article is interested in, the groups are:

1 The free trade approach, (this is better called unregulated trade as is it is questionable what is meant by the word 'free' in this context and who or what is free. The market forces are supposed to work freely in this approach. This however does not mean that as a result the freedom of the people within the markets is maximised, although this suggestion underlies the constant use of the word 'free' within the mainstream economic discourse. From a scientific perspective such leading use of words must be avoided to remain within the area of facts and not to move towards opinion about what is personally desired).

2 The 'structuralist' approach is based on the critique along the lines mentioned above, the infant industry argument, the terms of trade debate and further more recently developed arguments that will be addressed in due course in this article. This approach accepts the basic principles of international trade theory and agrees that trade is beneficial in a static and dynamic perspective, but it observes economic reality carefully and derives differentiated proposals based on practical observations to make the proposals realistic and corresponding to the evolutionary real world.

3 Interdependence theories that try to establish a link between trade and underdevelopment or try to explain that there must always be someone loosing if market transactions form the basis of international trade.

\subsection{The structuralist approach as the main theoretical basis}

The interdependence theories have in recent times lost considerable ground. Particularly the dynamic aspects of the international trade have empirically shown that the opinion that there cannot be a win-win situation in international trade is difficult to support. The interdependence theories had historically much support from a Marxist perspective 
which with the decline in interest in centrally planned economic systems have contributed to the decline of the interdependence theories. Problems with particularly excessive import substitution policies have shown that alternatives suggested are not free of problems either. As a consequence the debate moved more towards a realistic assessment of reality rather than developing more and more complicated theoretical concepts that move further and further away from reality and becomes more and more dependent on a particular set of assumptions. The problem with the current trade debate is that a significant number of the most active critics of globalisation tend to follow an approach similar in its result to the interdependence theories. Radical criticism of globalisation tends to try to prove the principle of comparative advantage wrong. This is a misplaced criticism as the principle is not wrong but is used in the wrong context and without regard for its true nature and limitations. Such criticism of the specific principle is often in conjunction with the attempt to prove trade as inherently harmful to economic development. Such proposals are not backed by empirical evidence and are highly questionable given many historic and present cases of success where countries after integrating themselves into the world economy have shown a good economic performance. As a consequence such unfounded statements should be avoided if any meaningful impact is going to be made on the overwhelming existing beliefs about the alleged economic necessity of a particular version of unregulated world trade.

The unregulated trade approach tends to fall into a similar trap, being however historically more successful than the interdependence theories, not only theoretically but empirically as well. As the basic principles appear to suggest precisely what the proponents want the international economic world to be, there is a strong interest in not developing the concepts further in a more differentiated way. There is instead a high level of intention in forming assumptions and constructing the models not with the idea of explaining reality as it is but to make suggestions on how the economic policies can help to shape the world, so that people within the markets are forced to behave in a way dictated by the need to maintain the economic status quo, rather than the need to maximise their 'real freedom' - however defined. Again, in the name of truly scientific approach such intention should be absent from any research and as a consequence international trade theory must deal with the reality as it is, not as it is normatively desired. There is in addition evidence that practical economic policies based on the unregulated trade concept implemented in addition with other neo-liberal concepts have failed to perform as desired. Increasingly countries, particularly within the developing world, are abandoning these ideas and try to establish an own strategy for development.

The approach that is therefore further advocated in this article is the 'structuralist' approach that tries to use the undeniable benefits of trade but assumes that an intelligent regulation or management of such trade achieves better results and increase trade relations and volume of trade. The unregulated trade approach, contrary to its aims, will not maximise the benefits from trade for the participants and may actually result in less trade being created in the long run as the economic problems it causes will lead to unsophisticated protectionist tendencies and continuing trade disputes caused by imbalances in trade. These eventualities are counter-productive to trade's fundamental basis.

The approach advocated in this article is the development of a modern trade approach that takes into account the limitations of the basic theoretical concepts and appreciates in particular the fundamental problems many underdeveloped countries are facing in getting a sustainable path of economic development started. Where a debate takes issue with the 
fundamental benefits of trade, this debate is likely to be lost by the critics. Debating the flawed structure, the inadequate quality of trade, focuses the debate on what really matters and targets the weaknesses of the conventional theories and principles directly.

The development of a progressive economic alternative to mainstream economics will have much better arguments to draw on and can only be successful if the proposals made are of a high quality nature and entirely in line with reality.

The concept of unregulated trade remains widely supported, despite the recent failure of economic policies based on neo-liberal ideas in central Europe among other regions of the world but most notably in Latin-America where the alternatives are now most actively being developed. See the World Development Reports for details of the current performance of individual countries (World Bank, various years) where it becomes evident that the empirical evidence does not support the neo-liberal development experiments as being clearly superior to other strategies. The theoretical dominance of conventional concepts will however continue until a comprehensive alternative in the form of an intelligent framework of international economic policies is developed. Current developments in international trade are very helpful to developing such an alternative and are now explained in more detail.

\section{Recent developments in international trade}

\subsection{Internationalisation and globalisation - economic style and economic system}

The debate about international economic issues is focused on the phenomenon of globalisation, which appears to be, according to many, an undeniable fact of life. This however depends on how the phenomenon is defined. Most definitions seem to follow the logic that increasing international trade is equivalent to globalisation. Only a superficial assessment of the criticism raised about the phenomenon globalisation suggests, however, that international trade itself is not the problem, but rather the tendency from international trade to induce reductions in social standards and the preference for automatic market driven outcomes over political design even if undesirable results are already clearly visible. In short the rolling back of previous achievements on the national economic level appears to cause most concern and is the basis for the intense public debate about the subject in many European countries and worldwide.

There seems to be a great difference between international trade as such and the way it is used to push a particular style of running the global economy. In the same way as there is a huge difference between the economic system that is principally used, the market economy, and the style in which it is run, a harsh capitalistic style or a more moderate and cooperative style, etc.

Similar to the above difference in economic system versus economic style a distinction between internationalisation and globalisation is suggested in this article. This distinction should lead to a more meaningful debate and avoids the constant confusion about what is actually criticised (Gruppe von Lissabon, 1997). It is suggested that internationalisation refers to the creation of more international trade, that is all. This is not a new process but a process that has intensified in recent decades. Globalisation is in contrast a new development and describes the particular neo-liberal agenda that has been given to the international economy - an agenda assumed as inevitable and used as 
the basis to propose economic policies down to the national and local level derived from the allegedly uncontrollable and unchangeable conditions in the international marketplace. Globalisation is the style of doing things, it does not refer to the international economy itself - the exchange of goods as such. It is no coincidence that the neo-liberal supporters of globalisation try to avoid such a distinction between system and style wherever they can in the same way as they tried to explain over past decades that the decision for a market economy is inevitably a decision for a particular type of society or a certain set of norms how people should behave, a particular style to run the economy. This article argues however that making the conscious decision to get involved in more trade because of the benefits it brings has nothing to do with determining what an intelligent way of establishing sound economic policies for such a scenario might be, particularly given the deficiencies of basic principles used to justify the simplistic belief that everything works automatically and generates optimal outcomes.

With the suggested definition above it becomes possible to concentrate the debate on what really matters as far as globalisation is concerned, that is the attempt to roll out a normatively desired but already increasingly publicly criticised way to run the international economy. The same logic is proposed by mainstream economics that was decades and centuries ago employed at a national level to prevent the development of a framework for progressive economic policies but is now strategically revived on the international level where there is not the same set of regulatory political bodies available as the political integration lags behind the economic integration. The important point from the above considerations about a sensible definition of globalisation is that keeping a useful definition in mind when addressing the subject of globalisation avoids a debate that is wrongly focused on the already decided question of whether trade is beneficial. The debate can then instantly focus on the economic style in which the increased internationalisation of economies is to be run and what the appropriate objectively justifiable economic policies for such a process should be, rather than questioning the entire internationalisation of the economy, which is quite clearly lost ground for any sensible political group or movement.

\subsection{Intra industry trade}

This change in perspective is necessary to focus the debate, correct those areas where criticism has been misplaced and to analyse current trends in international economic activity with the aim of developing the appropriate economic policies required. Further arguments that suggest a change of focus are now to be developed.

The era of globalisation is strongly linked with the activity of the so-called Trans-National Corporations (TNCs). The overwhelming volume of international trade is generated by TNCs. At the same time most of the trade is happening within very similar industries, the so-called intra industry trade. This means very similar goods are traded between countries with no apparent pattern of comparative advantage being utilised.

France is selling cars to Germany and German cars are sold in France. Who has the comparative advantage in the production of cars?

The very concept of comparative advantage appears to be becoming less and less relevant for explaining what is going on in the modern era of intra industry trade. The concept of comparative advantage was derived at a time where trade was based on so called complementary goods, goods that are very different from another, and are typically used together in the production process - they complement each other. The modern trade 
tends to be a trade in so-called substitutes, very similar products that can be used interchangeably. The relationship between intra industry trade and the question of whether complementary or substitutive items are traded is relatively complicated. It is quite possible that intra industry trade can occur in complementary products as well as for example a trade in car parts may occur between countries, car parts being clearly complementary products to cars. It is however the case that the modern intra industry trade can be defined as occurring between similar product categories in similar industries, this trend is undeniably correct. Although comparative advantage is now routinely used - often by those who do not fully understand it - to explain the superiority of 'free' unregulated trade, the trend towards globalisation is rapidly eroding the relevance of the concept itself.

It just cannot explain the intra industry trade mentioned above. In fact it is probably only relevant for traditional trade in raw materials and products that have to be produced in a certain geographical or climatic location. All other products of a more sophisticated knowledge based nature can principally be produced everywhere - comparative advantage has no value in determining what is or should be possible, efficient and beneficial under such circumstances. It can under no circumstances determine an optimal solution and is no bar to government exerting political will to change the current structure of trade, based on requirements of environmental protection, social security or a trade regime that is designed to benefit developing countries, to mention only the most pressing global problems of humankind. The deck of cards needs to be reshuffled and then a new game can start. Such an arrangement may result in an optimal solution being derived. The economic reality is remarkably different to such an arrangement, nothing is ever reshuffled and newly distributed and conventional economics is surprisingly uncritical about the significant cumulative effects that are existing as a consequence of the absence to such a redistributive arrangement despite the fact that such considerations are of prime importance for the development of meaningful macroeconomic theories.

Conventional thinking suggests that managing trade disturbs the principle of comparative advantage as soon as something is done and is therefore rejected as leading to inferior solutions. However, if this suggested automatic tendency to an optimal solution is no longer valid, as intra industry trade does not follow the traditional logic of comparative advantage in the first place, where is then the inevitable damage caused by such adjusting policies? In addition there is further debate on the effects of TNCs on the economic situation of developing countries in particular that will be later assessed in some detail. For a comprehensive summary of this issue see Jenkins (1987).

\subsection{Patterns of world trade stick to those countries already successful}

A further argument against the optimality assumption can yet again be derived from simple observation of reality. We are told that trade left to its own rules benefits everyone as there is the potential that even countries that have no single absolute advantage in any of their products can trade with others due to comparative advantage. Despite this brilliant, undeniable logic, trade patterns in the real world appear to be following a different dynamic trend. There is in fact a strong concentration of trade not only on the biggest TNCs being responsible for much of world trade but equally in geographical terms. The main industrialised countries in Europe and North America together with countries like Japan, Brazil, maybe Australia, and increasingly China and India, account 
for an overwhelming volume of trade - the rest of the world may in absolute terms still trade more but becomes increasingly unimportant in relative terms. The 'world trade' is actually bypassing most of the world. This type of concentration on few businesses or few regions is a very typical feature of economic systems that are left to market forces and are not managed by any conscious effort.

The traditional economic models most frequently fail to explain such concentrations due to their static nature, where developments over time do not play any role. If dynamic models are created they are designed to show the beneficial developments of market forces. The huge cumulative and concentrating tendencies, that the rich get richer much quicker than the poor get richer is not modelled with the same academic interest. These concentration and cumulative effects, based on the fact that no new rounds of a game are initiated like in a card game but a continuous movement from the already achieved basis is allowed to occur unchanged, are one of the many areas where a comprehensive reassessment of traditional economic thinking is required. The complexity of the arguments required to develop an alternative viewpoint explaining the cause of such concentrations cannot be developed any further here. However this will inevitably be a prime area of future debate, about the development of a more responsible economic framework for national and global economies.

In another even more important and fundamental area, that of the nature of business activity, we find the same lack of interest in combining known economic knowledge, with empirical evidence and then questioning how very simple pieces of logic can explain complex reality.

\subsection{The nature of business activity}

The question is about why businesses, and that includes the TNCs, actually exist in the first place. The argument that is to be developed is about the very nature of businesses: the bigger the business the more puzzling is its mere existence from a perspective based on the concept that market transactions are the most efficient way to coordinate economic activity. Conventional economic thinking tells us that the exchange of goods via market transactions is the preferred way of coordination and there is no doubt that this is correct in principle - hence the superiority of the market economy as the chosen economic system. So why is it then not the case that we are all self employed individuals working together by exchanging our services on an entirely individual basis via the market? Why is it the case that the work of people is organised by businesses that use hierarchies and formal concepts for the organisation of work that differs from the decentralised way of market transactions? Or more to the point, in the case of the TNCs, why is it the case that these huge businesses manage the international trade within their organisations and are increasingly replacing traditional import and export via markets with their own internal structures and network of sister companies worldwide?

What is happening with these multinationals is that they set up subsidiaries in foreign countries, joint ventures with other businesses or get involved in alliances with businesses in foreign countries. On the basis of such agreements, a long-term framework of business relations is established which is used to conduct the individual foreign transaction. This has nothing to do with the traditional market based approach of goods being exchanged in a decentralised way. 


\subsection{The transaction cost approach}

The reasoning behind this concept can be explained by the transaction cost approach first identified in detail in an article named 'The nature of the firm' (Coase, 1937) where the high transaction costs of an entirely market based approach are identified as the reason for the establishment of alternative structures - these structures being businesses as the alternative to decentralised markets. This principal idea about the nature of businesses remained unused for decades until with the emergence of the TNCs it became highly relevant for international trade theory. The TNCs are dominating international trade to such an extent because market transactions on a global scale are simply not the best approach to the question of organisation. The structure of the existing international trade increasingly contradicts the mainstream economic theory, which argues that the basis of international trade needs to be an unrestricted market force based approach.

The concept of comparative advantage cannot explain the increasing intra industry trade and the dominance of international trade by the TNCs that have largely replaced the old market based system with centralised structures. Despite this, comparative advantage is used as a central pillar of the argument for unrestricted free trade and globalisation. The traditional foundation for such statements is getting weaker and weaker right at a time when the arguments based on it try to fundamentally outline how the entire world economy is to be designed and run.

In addition to the transaction cost argument there are further reasons why decentralised, short-term market transactions may have to be replaced by other means of organisation. These structures may, in turn, eventually help to provide solutions for an effective organisation of global economic developments in a constructive way. The market itself is however likely to be insufficient to coordinate the processes in complex transactions.

Let us assume that a major construction project, maybe a power plant is to be built. Highly specialised equipment has to be combined with the building structure to make it work and all this is happening in a foreign country with a legal system different to many developed countries. The construction work starts and when it has reached the stage of completion for the technical equipment to be fitted the appropriate suppliers are invited to perform their task. Now where the specific construction work has been performed, so that only the equipment of a particular supplier will fit the building, this supplier claims that they had various production problems that resulted in much higher production costs to be charged for the delivery of the equipment, whether true or not. What can be done in such a situation? Re-negotiating with a different supplier requires major constructional changes. Enforcing the existing contract? The legal system in many underdeveloped countries is poorly established and the serious delays all this causes will threaten the profitability of the whole activity anyway.

These are the practical problems with the theoretically beneficial and efficient spot transactions based on quick and flexible markets, that do not appear in the simple theories. Uncertainties are mounting, problems are accumulating. Small business are not very likely to survive such problems and is for that very reason that they are not typically involved in much international activity. The TNCs are precisely for such reasons trying to establish alternative concepts for these complex transactions and are, as they managed to find an appropriate way to do so, dominating international trade to such an extent. If a joint venture is established where all participants are sharing the success of the final outcome this can help to avoid simple short run opportunism along the above mentions 
lines. This is another strong argument why the short sighted market based approach may have been appropriate for19th century transactions that where rather simplistic and based on uniform and complementary products. The modern world has moved on and requires different more sophisticated concepts of organisation and stakeholder arrangements.

Traditional and simplistic concepts of international trade are eroded, cannot explain modern forms of intra industry trade, which is irrelevant for modern trade, are unable to explain the existence of cumulative effects that lead to concentration of trade, are ignoring problems with persisting trade deficits and surpluses and cannot grasp the basic principles behind the very TNCs that form the backbone of international trade and the use of alternative organisational concepts. Simultaneously the argument persists that these clearly outdated trade concepts form the basis of a profoundly uninspiring concept for international trade and include the suggestion that explains to the world that there is no alternative to an approach in international economics that avoids any conscious political design.

There has hardly been a more prominent case where the attempt has been made to explain so much economic reality in such an important political area with so little convincing theoretical foundation. Right at the time where the traditional foundation of international economic theory appears to be outdated to say the least, this approach is used to advertise this most fundamental approach to the entire economic world to leave things to precisely these market forces and any attempts to try to introduce some form of management into what is going on along democratically agreed principles by elected politicians is rejected as reducing the dynamic benefits of trade. This is effectively a desperately defensive ground for a science that is unlikely to be a persistent basis for international economic policies.

\subsection{New concepts in managed trade}

International trade is one of the prime areas for a change in economic thinking towards more proven and fact based principles, rather than the constant attempt to revive old concepts only because they fit the traditional mainstream thinking and help to keep the world organised in the same way as in the past.

The above mentioned modern developments in international trade allow us to intellectually reduce traditional concepts to what they actually are, basic principles that require many differentiated additions before they can be used to explain reality or be used for suggesting or selecting political concepts. The new developments are also the potential basis for a completely new approach in international economics. If it is the case that the best organisational principle for the more complex nature of international economic transactions is a concept of organisation higher than the decentralised market level, should it then not be possible that such an organisation is based on public bodies managing the global economy according to agreed and set standards. This would allow us to achieve the undeniable benefits of trade in a way that avoids competing relevant environmental or social standards downwards or cause all the hardship for people in an overly competitive environment - which is the starting point for the critical debate on globalisation.

If TNCs can manage trade in the way mentioned above, why is it then not possible that a modern trade regime along the 'structuralist' critique, based on the acceptance of modern economic reality, and based on wider more holistic values, can be achieved? Why is it the case that any government or supra national political activity is inevitably 
restricting the benefits of trade where the management by TNCs of the very same trade according to their requirements is the standard these days and tends not to be criticised by mainstream economics.

The arguments based on simplistic trade principles are getting weaker in the modern trade environment. They cannot form the basis of the future of international economics, they are not the ultimate say about the reality we live in, they are a continuing attempt to prolong the life of traditional values that can only survive when the national and international economy is kept on a strictly competitive basis regardless of the dynamics this results in or whether the goals have lost its meaning and value long before. All this is in strict contradiction to a more progressive approach in economics that starts with meaningful and objective goals and derives practical concepts from a truthful assessment of reality to achieve these goals and is furthermore stating clearly that such considerations can never be entirely scientific as it includes inevitably normative elements.

The current developments in international trade provide a great opportunity for such a modern approach as it becomes apparent that the trade is already organised, only by different bodies. The argument that trade cannot or should not be organised or managed is out of touch with reality. The existing international trade bodies are just required to change their agenda in line with more recent developments and allow for detailed and specific economic policies that manage international trade on the local, national and global level with the international body supervising the policies to keep them in line with agreed standards and avoiding any drifting into unsystematic protectionism.

It has however to be emphasised that only realistic concepts will help to achieve the establishment of a concept of managed trade along developing economics, environmental and social requirements of the modern world. As mentioned before it is not advisable to start a debate in this matter based on an ill-informed critique of basic principles that cannot be criticised as such, as they are logically correct. Similarly, time should not be wasted on constantly trying to deny empirical evidence or to suggest a simple alternative anti trade concept. The problems with international trade particularly faced by developing countries, are so complex and difficult that nobody should quickly favour one particular alternative concept or jump to conclusions, whether they are neo-liberal or not. We need to keep options open and experiment with them. Nobody knows what really works in international trade and how the underdevelopment in this world with related overpopulation and environmental problems can be solved. But we should know now that we need better concepts than the outdated conventional mainstream idea of an automatic optimal solution. The criticism of globalisation as a style of running the world economy is very valid - the problem is that the criticisms raised are more often than not outside the above outlined concept of a realistic strategy with which the subject is addressed appropriately.

As the reader can see from this text almost all elements that are required for an alternative concept have been derived long ago, they just need to be picked up and combined in the appropriate way. If we do not find an alternative way to manage trade we will be pulled down by the magnitude of the existing practical deficiencies in many countries and the loss of dynamism in the economy. Nor is it appropriate to try to develop radical alternatives that only help mainstream arguments as they are easily contradicted. The main challenge in economic thinking and research remains, in this and other specialist subjects, to avoid being trapped by conventional concepts that were derived for 
a different time and economic situation. If the evolutionary nature of the economy is correctly taken into account the problems appear less unmanageable than before. If only some significant players or international bodies involved in trade negotiations follow this new strategy they will soon change the characteristics of trade negotiation rounds and will regain the support of the general public. A consensus between the developed and less developed world could be established to decide on the global protection of standards. This might avoid a competitive spiral downwards and the strong criticism of the internationalised economy can be guided to a more constructive path. On that basis unsystematic protectionism can be avoided and the world economy might flourish, being based on economic policies that monitor the quality of processes right from the start. Without such a change in strategy, the existing international bodies will have to solve increasing numbers of conflicts and will struggle to maintain a decently functioning world economy. Only progressive, economic policies are able to combine economic progress, as well as ensuring the involvement of more people in the world economy and also achieving social and environmental justice as a strategic principle. Such a strategic principle would then become a core aim and no longer just a vague optional add-on, which may or may not be achieved much later or never.

\section{References}

Chang, H-J. (2004) Reclaiming Development - An Alternative Economic Policy Manual, London: Zed Books.

Coase, R. (1988) 'The nature of the firm', Journal of Law, Economics and Organisation, Oxford University Press, Vol. 4, No. 1, pp.3-17 (Original 1937).

Eucken, W. (1990) Grundsätze der Wirtschaftspolitik, 6. Aufl., Tübingen, (1. Aufl. 1952).

Greenaway, D. and Shaw, G.K. (1988) Macroeconomics, 2nd ed., Basil Blackwell.

Grimwade, N. (2000) International Trade: New Patterns of Trade, Production and Investment, London.

Gruppe von Lissabon (1997) Grenzen des Wettbewerbs, Luchterhand.

Heinemann, V. (2001) Die Oekonomie der Zukunft, books on demand, Hamburg.

Ietto-Gillies, G. (2005) Transnational Corporations and International Production - Concepts, Theories and Effects, Cheltenham.

Jenkins, R. (1987) Transnational Corporations and uneven development - The Internationalisation of Capital and the Third World, London: Routledge.

Keynes, J.M. (1936) The General Theory of Employment, Interest and Money, London, New York.

List, F. (1856) The National System of Political Economy, Philadelphia: Lippincott.

Olson, M. (1991) Aufstieg und Niedergang von Nationen, Ökonomisches Wachstum, Stagflation und soziale Starrheit, 2. Aufl., Tübingen.

Paetzold, J. (1998) Stabilisierungspolitik, Grundlagen der nachfrage und angebotsorientierten Wirtschaftspolitik, 6. Aufl, UTB, Bern und Stuttgart.

Pareto, V. (1909) Manual of Political Economy, English translation by A. Schwier 1971, New York: Augustus M Kelly (Original 1906).

Porter, M. (1990) The Competitive Advantage of Nations, London: Macmillan Press.

Prebisch, R. (1950) 'The economic development of Latin America and its principal problems', Economic Bulletin for Latin America, Vol. 7, pp.1-12.

Ricardo, D. (1821) On the Principles of Political Economy and Taxation, 3rd ed., London: John Murray (Original 1817). 
Sachverstaendigenrat zur Begutachtung der Gesamtwirtschaftlichen Entwicklung (various years) Annual Reports, Wiesbaden, Statistisches Bundesamt.

Schumpeter, J.A. (1997) 'Theorie der wirtschaftlichen Entwicklung', Eine Untersuchung über Unternehmensgewinn, Kapital, Kredit, Zins und Konjunkturzyklus, 9. Aufl., Berlin (Original 1911).

Screpanti, E. and Zamagni, S. (2005) An Outline of the History of Economic Thought, 2nd ed., Oxford University Press.

Singer, H. (1950) 'Comments to the terms of trade and economic development', Review of Economics and Statistics, Vol. 40, pp.84-89.

Smith, A. (1904) An Inquiry into the Nature and the Causes of the Wealth of Nations, Dent \& Sons (Original 1776).

Woodin, M. and Lucas, C. (2004) Green Alternatives to Globalisation, London: Pluto Press.

World Bank World (various years) World Development Report, The World Bank, Washington. 